\title{
In-situ characterization of discharge products of lithium-oxygen battery using Flow Electrochemical Atomic Force Microscopy
}

\author{
Henry A. Cortés ${ }^{a}$ and Horacio R. Corti ${ }^{a, b *}$ \\ ${ }^{a}$ Departamento de Física de la Materia Condensada e Instituto de Nanociencia y Nanotecnología \\ (INN-CONICET) Comisión Nacional de Energía Atómica \\ Avda. General Paz 1499, 1650 San Martín, Buenos Aires (Argentina) \\ ${ }^{b}$ Instituto de Química Física de los Materiales Medio Ambiente y Energía (INQUIMAE-CONICET) \\ Facultad de Ciencias Exactas y Naturales, Universidad de Buenos Aires \\ Pabellón II, Ciudad Universitaria, 1428 Buenos Aires (Argentina) \\ E-mail: hrcorti@tandar.cnea.gov.ar
}




\begin{abstract}
The increasing interest in lithium-oxygen batteries (LOB), having the highest theoretical energy densities among the advanced lithium batteries, has triggered the search for in-situ characterization techniques, including Electrochemical Atomic Force Microscopy (EC-AFM). In this work we addressed the characterization of the formation and decomposition of lithium peroxide $\left(\mathrm{Li}_{2} \mathrm{O}_{2}\right)$ on a carbon cathode using a modified AFM technique, called Flow Electrochemical Atomic Force Microscopy (FE-AFM), where an oxygen-saturated solution of the non-aqueous lithium electrolyte is circulated through a liquid AFM cell. This novel technique does not require keeping the AFM equipment inside a glove-box, and it allows performing a number of experiments using the same substrate with different electrolytes without dissembling the cell. We study the morphology of $\mathrm{Li}_{2} \mathrm{O}_{2}$ on graphite carbon using lithium bis(trifluoromethane sulfonyl)imide (LiTFSI) in dimethyl sulphoxide (DMSO) as electrolyte under different operational conditions and compare our results with those reported using other electrolytes and in-situ and ex-situ EC-AFM.
\end{abstract}

Keywords: Atomic force microscopy, Lithium-oxygen battery, flow-cell, discharge products. 


\section{Introduction}

Since it was described for the first time by Abraham and Jiang in $1996,{ }^{1}$ the Li-O ${ }_{2}$ battery (LOB) has attracted enormous research attention, aiming to approach its outstanding theoretical energy density, ${ }^{2}$ close to 3500 Wh. $\mathrm{kg}^{-1}$, needed to improve the autonomy of electrical vehicles beyond the limit imposed by the Li-ion batteries. It is now well-known that there are important technical challenges for developing any practical LOB, namely, high charge potential, low discharge capacities, and poor electrolyte and cathode stability that strongly limit discharge-charge cycle efficiency and power density. ${ }^{3-6}$

The mechanisms of the oxygen reduction reaction (ORR) and the oxygen evolution reaction (OER) in a LOB operating with aprotic solvents have been clarified by several authors. ${ }^{711}$ Thus, the ORR discharge reaction leading to the formation of $\mathrm{Li}_{2} \mathrm{O}_{2}$ on the cathode can occurs through surface or solution routes where, in both cases, the first step is the reduction of $\mathrm{O}_{2}$ to the superoxide radical $\left(\mathrm{O}_{2}^{--}\right)$. A solution mechanism takes place in solvents with high donor number, where the superoxide ion forms ion pairs and higher aggregates with $\mathrm{Li}^{+}$ions in the solution, which diffuse before chemical disproportion into $\mathrm{Li}_{2} \mathrm{O}_{2}$, leading to the formation of a thick layer. Solvents with low donor number promote the surface mechanism, leading to thin films $(<10 \mathrm{~nm}$ in thickness $)$ due to the insulating nature of the deposit that self limit its growth.

The dissociation degree of the lithium salt also seems to affect the morphology of the $\mathrm{Li}_{2} \mathrm{O}_{2}$ deposits. ${ }^{12}$ Thus, a "bottom-up" $\mathrm{Li}_{2} \mathrm{O}_{2}$ precipitation mechanism operates with highly dissociated Li salts, such as LiTFSI in low-DN glymes, forming a thin layer of the product that cover the surface till the electrons cannot penetrate further and the discharge process stops. On contrary, for highly associated salts, such as $\mathrm{LiNO}_{3}$ in diglyme, a "top-down" precipitation mechanism that expands in 
all directions takes place, leading to large deposits. However, since the degree of the lithium salt association depends on a balance between the interaction of the $\mathrm{Li}^{+}$ions with the solvent and the counteranion, ${ }^{13}$ it is not straightforward to predict the type of deposit that can be formed in a LOB under a given choice of salt and solvent.

For this reason, the direct observation of morphology of the cathodic product during the discharge, and its subsequent dissolution (oxygen evolution) during the charge cycle, is of crucial interest for the optimization of a LOB in order to improve the electrolyte performance. The use of Atomic Force Microscopy (AFM) is well known in the field of lithium batteries as a direct method to visualize the formation of the solid-electrolyte interphase (SEI) and the denditric formation in lithium-ion batteries (LIB). ${ }^{14,15}$ A recent review by Weidong et al.${ }^{16}$ briefly mentioned a few AFM studies describing the use of AFM for the characterization of LOBs. Thus, it is worth to review here the studies reported during the last years, which analyze the morphology and conductivity of the discharge products of LOB using AFM and Electrochemical Atomic Force Microscopy (EC-AFM), performed in-situ, ${ }^{17-22}$ and ex-situ. ${ }^{23-25}$

Byon and coworkers carried out the first in-situ study of the formation ${ }^{17}$ and decomposition ${ }^{18}$ of $\mathrm{Li}_{2} \mathrm{O}_{2}$ on HOPG (highly oriented pyrolytic graphite) using the EC-AFM technique, with $0.5 \mathrm{M}$ LiTFSI in TEGDME as electrolyte and metallic Li as counter-electrode. The AFM was located inside a glove-box and the contact mode AFM was realized with silicon nitride tips for the electrochemical scan and Si tips to observe the HOPG surface in tapping mode, once the cell was disabled. The $\mathrm{Li}_{2} \mathrm{O}_{2}$ deposit on HOPG terrace edges exhibited nanoplate shape having several hundred of nm length and $5 \mathrm{~nm}$ height, and they disappear during the oxygen evolution reaction (OER). A similar study on a mesoporous gold electrode using the same electrolyte, ${ }^{19}$ allowed to 
visualize the formation of a film of $\mathrm{Li}_{2} \mathrm{O}_{2}$ nanoparticles with sizes around $10 \mathrm{~nm}$, which grows up as the discharge proceeds, reaching a final size of $50 \mathrm{~nm}$.

Liu and $\mathrm{Ye}^{20}$ used in-situ EC-AFM to determine the morphology of the deposits on gold electrodes with $0.1 \mathrm{M} \mathrm{LiClO}_{4}$ in DMSO as electrolyte. They found that the shape of the $\mathrm{Li}_{2} \mathrm{O}_{2}$ nanoparticles depend on the water content of the electrolyte, and concluded that there is no evidence of a disproportion of $\mathrm{LiO}_{2}$ in solution for the formation of $\mathrm{Li}_{2} \mathrm{O}_{2}$ on the surface. The voltagram shows two cathodic peaks which were attributed to the formation of the superoxide ion followed by the formation of the peroxide. At a cathodic potential close to the first peak small particles were observed on the surface, which grow up when the second peak is reached. During the anodic scan, in an electrolyte containing $1000 \mathrm{ppm}$ of $\mathrm{H}_{2} \mathrm{O}$, three peaks of low intensity were observed, indicating that the species formed during the ORR are not fully oxidized during the OER. The two first anodic peaks were assigned to partial oxidation of the peroxide and superoxide (in solution) on the surface, but the process that originates the third peaks was not identified. If the electrolyte contains only $33 \mathrm{ppm}$ of $\mathrm{H}_{2} \mathrm{O}$, the cathodic voltagram only shows one peak, and the $\mathrm{Li}_{2} \mathrm{O}_{2}$ particles are smaller as the water content diminishes.

Shen et al. ${ }^{21}$ studied by EC-AFM the ORR/OER processes on HOPG using 0.5 M LiTFSI in DMSO with the addition of DBBQ (2,5-di-tert-butyl-1,4-benzoquinone) as soluble catalyst. The voltagrams show two cathodic peaks, attributed to the superoxide and peroxide formation, and three anodic peaks, the first one assigned to the superoxide oxidation and the other two to the peroxide oxidation. The AFM images in absence of DBBQ show the initial formation of $\mathrm{Li}_{2} \mathrm{O}_{2}$ of size around $5 \mathrm{~nm}$ when the first peak is approached, while a toroidal morphology around 300-400 $\mathrm{nm}$ in diameter are formed when the second peak is reached. During the charge process a 
bottom-up mechanism of toroid decomposition is observed. In the presence of DBBQ the $\mathrm{Li}_{2} \mathrm{O}_{2}$ deposit adopts a flower-like shape that decomposes from the outside to the inside during the OER. An AFM cell that allows the control of the atmosphere over the glassy carbon substrate was built by Virwani et al. ${ }^{22}$ They used $1 \mathrm{M} \mathrm{LiNO}_{3} 1 \mathrm{M}$ in TEGDME as electrolyte, with different water contents, and analyzed the topography of the deposits during the ORR and OER. A remarkable effect of the water content was observed on the deposit morphology and the discharge capacity of the cell. For instance, the cell capacity increases 11 times when the water content increase from 20 ppm to $4600 \mathrm{ppm}$. The $\mathrm{Li}_{2} \mathrm{O}_{2}$ deposits formed with small water contents exhibit spherical or bar shape in the range between 200 and $400 \mathrm{~nm}$, and they appear at the final of the discharge. With high water content, large toroidal particles $(\sim 400 \mathrm{~nm})$ are observed at the beginning of the discharge, while smaller ones are formed later.

Ex-situ AFM studies were performed by Calvo and coworkers using $0.1 \mathrm{M} \mathrm{LiPF}_{6}$ in DMSO on HOPG. ${ }^{23,24}$ In this case the cathodic voltagram has only one peak, while the anodic peaks were assigned to the oxidation of the superoxide, the solvent, and other products of reduction of oxygen. The particles deposited on the HOPG edges and terraces never exceed $12 \mathrm{~nm}$. The few particles deposited at low polarization are supposed to form by disproportion of the $\mathrm{LiO}_{2}$, while the massive deposit at higher cathodic potentials would be due to the superoxide reduction over the surface.

An ex-situ study on HOPG aimed to analyze the effect of the incorporation of chloride on the capacity of $\mathrm{LOB},{ }^{25}$ and it is the only AFM work where the electrical conductivity of the formed film was analyzed. The authors claim that an important increase in the film conductivity was detected by Conductive-AFM, when $\mathrm{Cl}^{-}$ions are added to the electrolyte. However, some doubts on the conclusions arise due to the lack of care when the film deposited on the electrode is transferred to the AFM cell. It is probable that the $\mathrm{Li}_{2} \mathrm{O}_{2}$ was converted to $\mathrm{LiOH}$ before the 
conductivity was measured with the AFM and also, that the high conductivity reported be a consequence of the contact of the Pt AFM tip with the HOPG surface in some places. In fact, DFT studies on $\mathrm{Li}_{2} \mathrm{O}_{2}$ structures doped with $\mathrm{Cl}^{-}$ions have proved that the conductivity of the systems is not altered by the presence of chloride or other halogen anions. ${ }^{26}$

In this work we have developed a novel procedure for in-situ observation of the deposit in a LOB during discharge/charge cycles, which can be performed without resorting to the use of a glove-box, making the technique more simple than previously reported in the literature. The technique was used to analyze the morphology of the $\mathrm{Li}_{2} \mathrm{O}_{2}$ deposit on highly oriented pyrolytic graphite (HOPG), using lithium bis(trifluoromethane sulfonyl)imide (LiTFSI) in dimethyl sulphoxide (DMSO) as electrolyte, under different operational conditions.

\section{Experimental}

\subsection{Materials.}

The electrolyte was prepared using anhydrous dimethyl sulfoxide (DMSO, > 99,9\%, Sigma-Aldrich) and lithium bis(trifluoromethane sulfonyl)imide (LiTFSI, Sigma-Aldrich, 99,95\%). The DMSO, dried during several days on $3 \AA$ molecular sieves (Sigma-Aldrich), had a water content $<50$ ppm, measured by Karl Fisher. The solution of LiTFSI in DMSO was prepared in a MBRAUN glove-box $\left(\mathrm{H}_{2} \mathrm{O}<3 \mathrm{ppm}\right.$ and $\left.\mathrm{O}_{2}<2 \mathrm{ppm}\right)$, and stored in $10 \mathrm{~cm}^{3}$ vessels sealed with rubber septum. Once removed from the glove-box the electrolyte was bubbled with dry $\mathrm{O}_{2}(>$ $99.5 \%)$ or $\operatorname{Ar}(>99.99 \%)$ during 40 minutes. In order to avoid the hydration of the electrolyte we used silica gel traps at the input and output of the vessel containing the electrolyte. 


\section{2,2 Flow Electrochemical Atomic Force Microscopy (FE-AFM)}

As indicated in the Introduction, the in-situ experiments related to the electrochemical study of the discharge products in LOB were performed in AFM located inside a glove-box. In this work we describe a novel procedure to perform such experiments without the limitations imposed by the glove-box.

To achieve this goal we have used a Veeco AFM (model NanoScope IIIa) along with a commercial AFM cell for liquids, adapted to include the corresponding electrodes, and integrated to a system of electrolyte delivery working in once-through flux mode. A full scheme of the FE-AFM equipment is depicted in Figure 1.

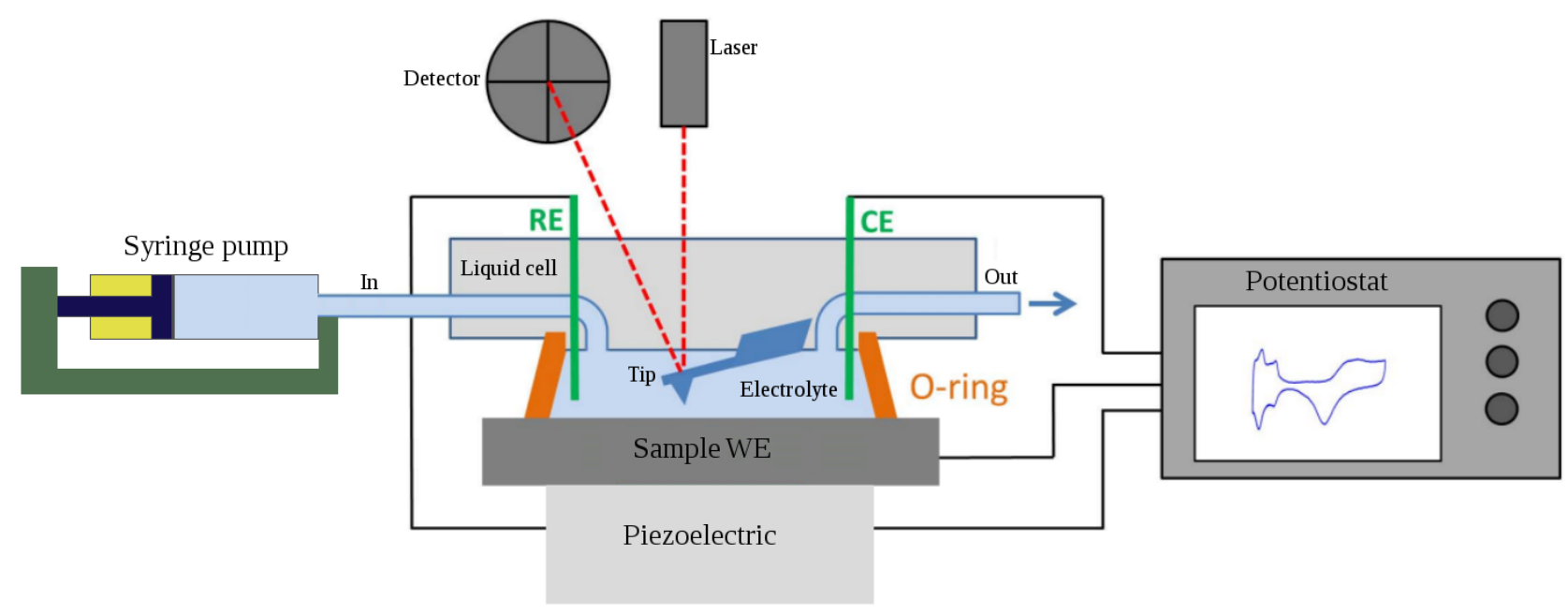

Figure 1. Scheme of the flow electrochemical AFM (FE-AFM).

\subsection{The FE-AFM cell.}


A general view of the glass AFM cell for liquid used for the FE-AFM studies is shown in Figure 2a. A detail of the glass AFM cell is depicted in Figures 2b-c. In the bottom view (Figure 2b) it can be observed the o'ring that is in contact with the working electrode (WE), a plate of exfoliated HOPG whose exposed area (limited by the o'ring) is $0.5 \mathrm{~cm}^{2}$. The volume of the cell, once it is assembled is around $0.024 \mathrm{~cm}^{3}$.

The counter-electrode (CE) was a Pt wire $(0.25 \mathrm{~mm}$ in diameter) inserted through the upper part of the glass cell (Figure 2c). The reference electrode (RE) was a $\mathrm{Ag}$ wire (1 $\mathrm{mm}$ in diameter) immersed in a small tube containing $0.1 \mathrm{M} \mathrm{AgNO}_{3} / \mathrm{DMSO}$ with a glass frit at the end (Figure 2d). The RE was located in one of the lateral channels of the glass cell (Figure 2b-c) in such a way that the liquid junction is close to the working electrode and sealed on the other extreme with PTFE. The potential of the $\mathrm{Ag} / \mathrm{Ag}^{+}$in DMSO was measured against a Li wire immersed in $0.5 \mathrm{M}$ LiTFSI in DMSO inside a glove-box. The measured potential was $3.87 \mathrm{~V}$, in agreement with the value reported in the literature. ${ }^{11}$

a)

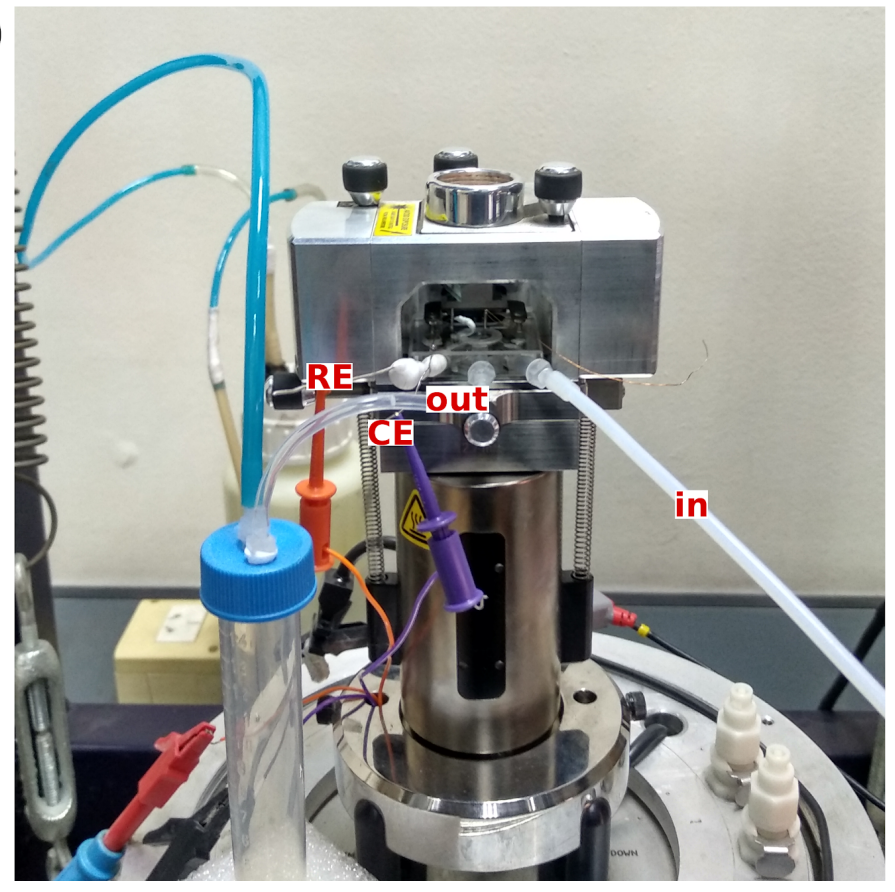

b)

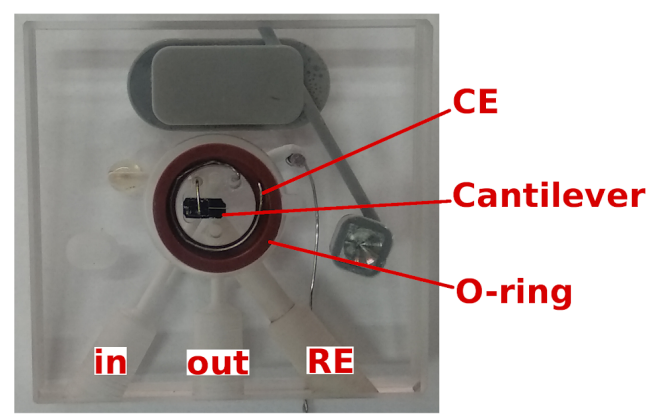

c)

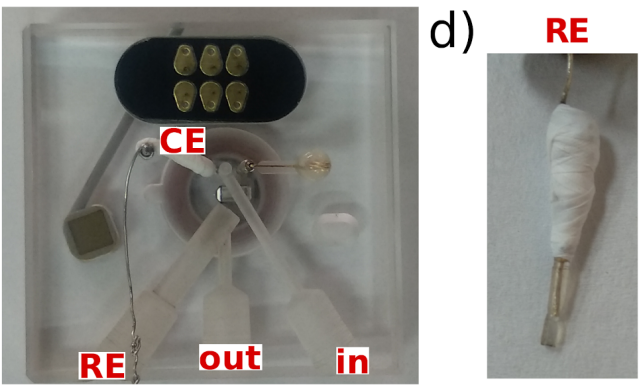

Figure 2. a) FE-AFM cell for liquids mounted on the AFM. The letters indicated the position of 
the counter-electrode (CE), reference electrode (RE) and the input (IN) and output (OUT) of electrolyte; b) and c) Cell for liquids, bottom and upper view, respectively, showing the channels for the electrodes and electrolyte flow; d) reference electrode.

The supporting electrolyte was injected into the cell with a mechanical syringe (APEMA, model PU11U) at a controlled flow which varied in the range $0.016-0.032 \mathrm{~cm}^{3} \cdot \mathrm{min}^{-1}$, that is, the resident time of the solution in the FE-AFM cell was around one minute, which it was enough to maintain an appropriated oxygen concentration on the working electrode.

The three electrodes were connected to a potentiostac (Autolab, model PGSTAT302N) and all the measured potential were referred to the couple $\mathrm{Li} / \mathrm{Li}^{+}$in DMSO.

\subsection{AFM Images}

The interphase electrolyte/HOPG was monitored with the AFM in tapping mode silicon nitride tips covered with Pt (HQ:NCS18/Pt), having force constant $5 \mathrm{~N} / \mathrm{m}$, and resonance frequency $75 \mathrm{kHz}$. A resonance frequency of $21 \mathrm{kHz}$ was chosen when the cantilever is immersed in the electrolyte. The image capture took around 260 seconds and the analysis was performed using the software Gwyddion 2.4. Each image was taken immediately after the electrochemical measurement, and the solution flow was interrupted during the image capture in order to optimize its quality.

\section{Results and discussion}

Figure 3 shows the $\mathrm{CV}$ of the cell in $0.5 \mathrm{M}$ LiTFSI/DMSO saturated with $\mathrm{O}_{2}$ and Ar. The scan rate was $50 \mathrm{mV} / \mathrm{s}$ from the OCP $(-3 \mathrm{~V})$ up to $2,0 \mathrm{~V}$ for the cathodic scan and from $2.0 \mathrm{~V}$ up to $4.8 \mathrm{~V}$ 
for the anodic scan. The $\mathrm{CV}$ for the $\mathrm{O}_{2}$ reduction show a two cathodic peaks at $2.80 \mathrm{~V}$ and $2.57 \mathrm{~V}$, attributed to the reduction of $\mathrm{O}_{2}$ to $\mathrm{LiO}_{2}$ and $\mathrm{Li}_{2} \mathrm{O}_{2}$, respectively.

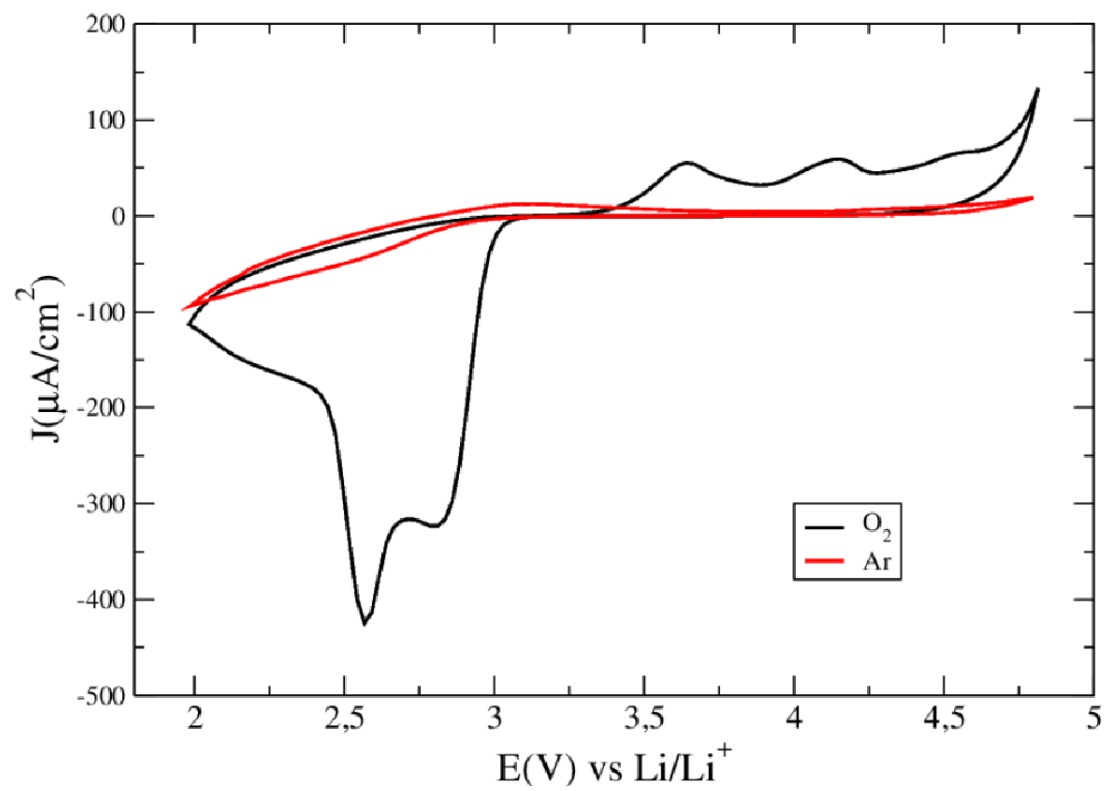

Figure 3. $\mathrm{CV}$ of $\mathrm{O}_{2}$-saturated (black) and Ar-saturated (red) 0.1 M LiTFSI/DMSO on HOPG (scan rate: $50 \mathrm{mV} / \mathrm{s})$.

The anodic branch of the $\mathrm{CV}$ exhibits three peaks at $3.64 \mathrm{~V}, 4.19 \mathrm{~V}$, and $4.53 \mathrm{~V}$ of lower intensity, indicating that the species formed during the ORR are not fully oxidized during the OER. The first peak was assigned to the oxidation of $\mathrm{LiO}_{2}$ and the other two to the oxidation of $\mathrm{Li}_{2} \mathrm{O}_{2} \cdot{ }^{5}$ No peaks were observed in the CV when the electrolyte saturated with Ar.

Figures 4a-d show the AFM images and topographic profiles of the HOPG surface taken during the CV shown in Figure 3. At the OCP (Figures 4a and 4d) it can be observed the characteristic steps and terraces of the HOPG. 

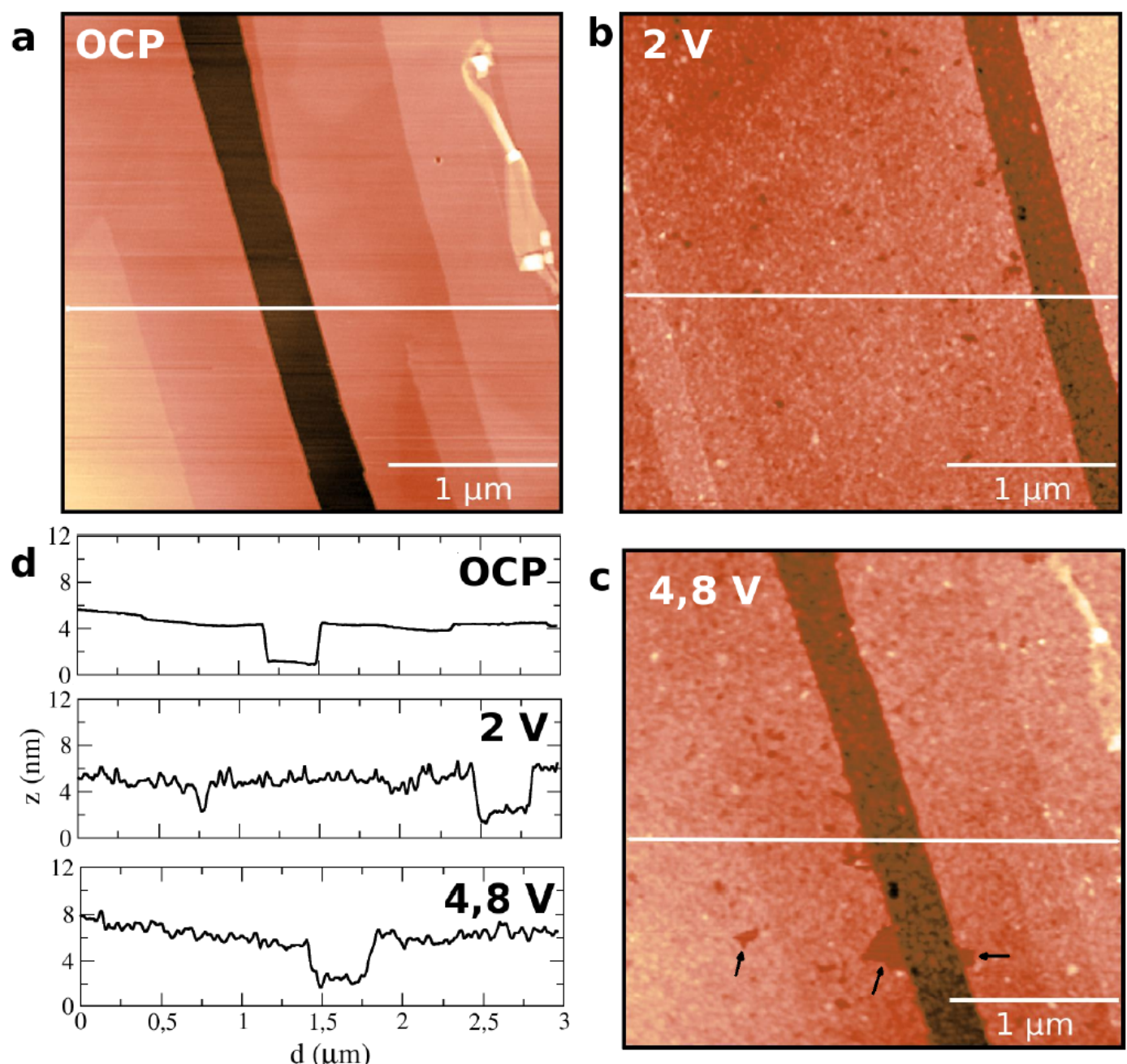

Figure 4. In situ AFM images of the HOPG surface at the potentials: a) OCP,b) 2 V, and c) 4,8 V after the CV indicated in Figure 2; d) Topographic profiles measured along the white lines indicated on the images.

After the cathodic scan, at $2.0 \mathrm{~V}$, a deposit of $\mathrm{Li}_{2} \mathrm{O}_{2}$ nanoparticles ( $3 \mathrm{~nm}$ height $)$ covers uniformly the HOPG surface (Figure 4b). After the anodic scan, at $4.8 \mathrm{~V}$, small holes appear in the deposit, revealing the oxidation of $\mathrm{Li}_{2} \mathrm{O}_{2}$, while the rest of the deposits remain stable (Figure $4 \mathrm{c}$ ). Meanwhile, the topographic profiles (Figure 4d), indicates that there is not significant changes in 
the deposit rugosity during the oxidation. This confirms that the deposit formed during the ORR is not fully oxidized during the OER.

Figure 5a shows the current density as a function of time during a chronoamperometry (CA) at an oxidation potential of $4.19 \mathrm{~V}$ during 150 seconds, performed after the CV (Figure 3). The fact the current density does not vanish, indicates the presence of a remainder $\mathrm{Li}_{2} \mathrm{O}_{2}$ deposit on the $\mathrm{HOPG}$ surface.
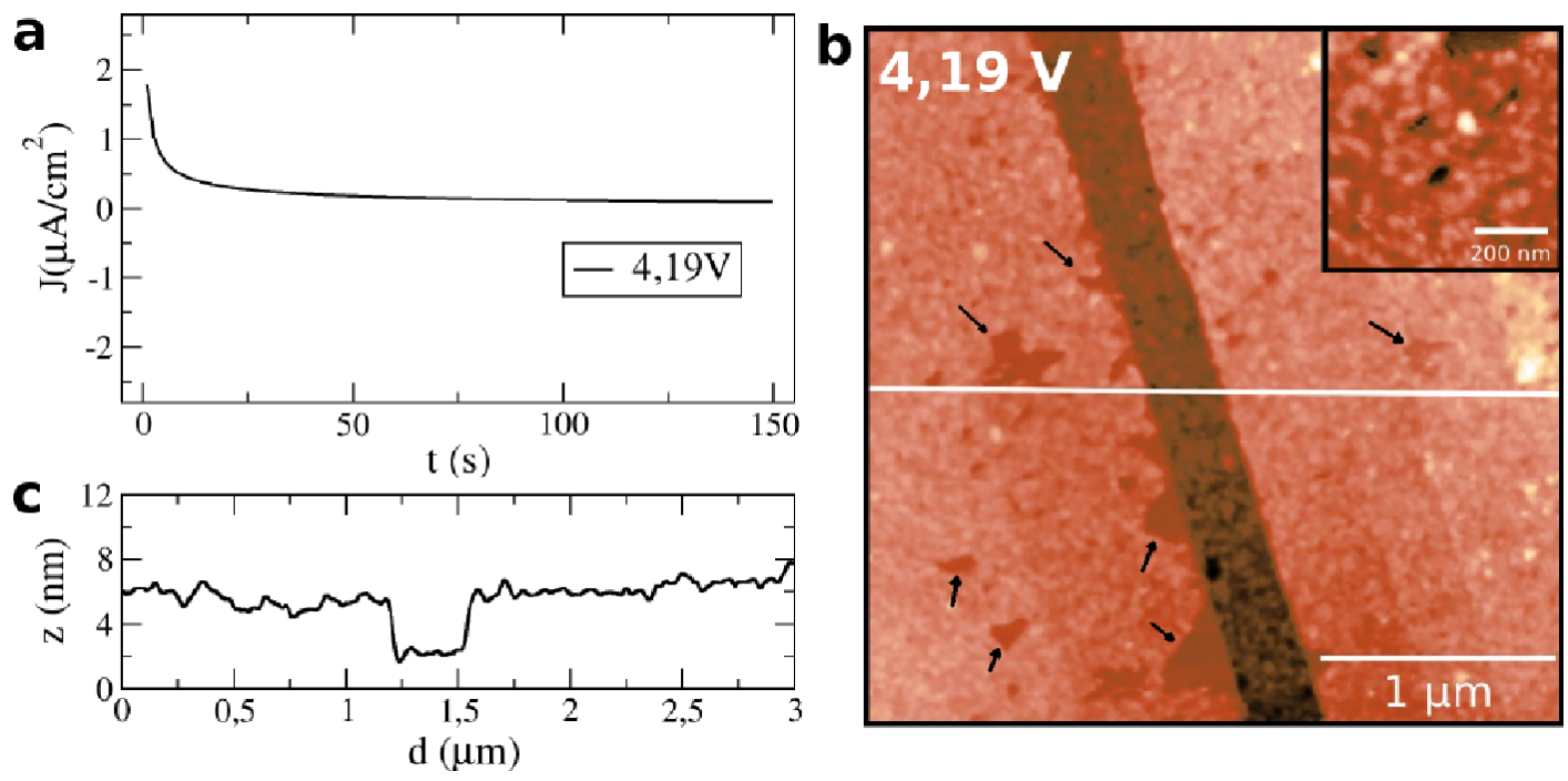

Figure 5. Oxidation of $\mathrm{Li}_{2} \mathrm{O}_{2}$ under chronoamperometry at $4.19 \mathrm{~V}$ during $150 \mathrm{~s}$ in LiTFSI $0.5 \mathrm{M}$ in $\mathrm{O}_{2}$-saturated DMSO. a) Current density as a function of time; b) In situ AFM image of HOPG surface after the OOR; c) Topographic profile measured along the white line indicated on the image.

This is also confirmed by the AFM image (Figure 5b), where the presence of this deposit is visualized. The size of the holes on the deposit increases during the oxidation process, and new holes appear, particularly near the step edges. In Figure 5c, the topographic profiles after the CA, 
reveals a slight decrease of the deposit roughness, suggesting a reduction in the particle height due to oxidation. These results agree with the scenario proposed by Byon et al., ${ }^{18}$ where the thinner parts of the $\mathrm{Li}_{2} \mathrm{O}_{2}$ deposit oxidize first, forming the small holes, while the broader parts oxidize in the lateral direction, being a limitation for the charge transport toward the $\mathrm{Li}_{2} \mathrm{O}_{2}$ surface.

Figure 6a shows the same current density vs. time and AFM image when the CA reaches 2300 seconds. The current density approaches zero as a consequence of the total oxidation of the $\mathrm{Li}_{2} \mathrm{O}_{2}$ deposit. Figure $6 \mathrm{~b}$ shows the AFM image of the HOPG surface free of $\mathrm{Li}_{2} \mathrm{O}_{2}$ deposits, a fact that is also evident observing the topographic profile (Figure 6c).

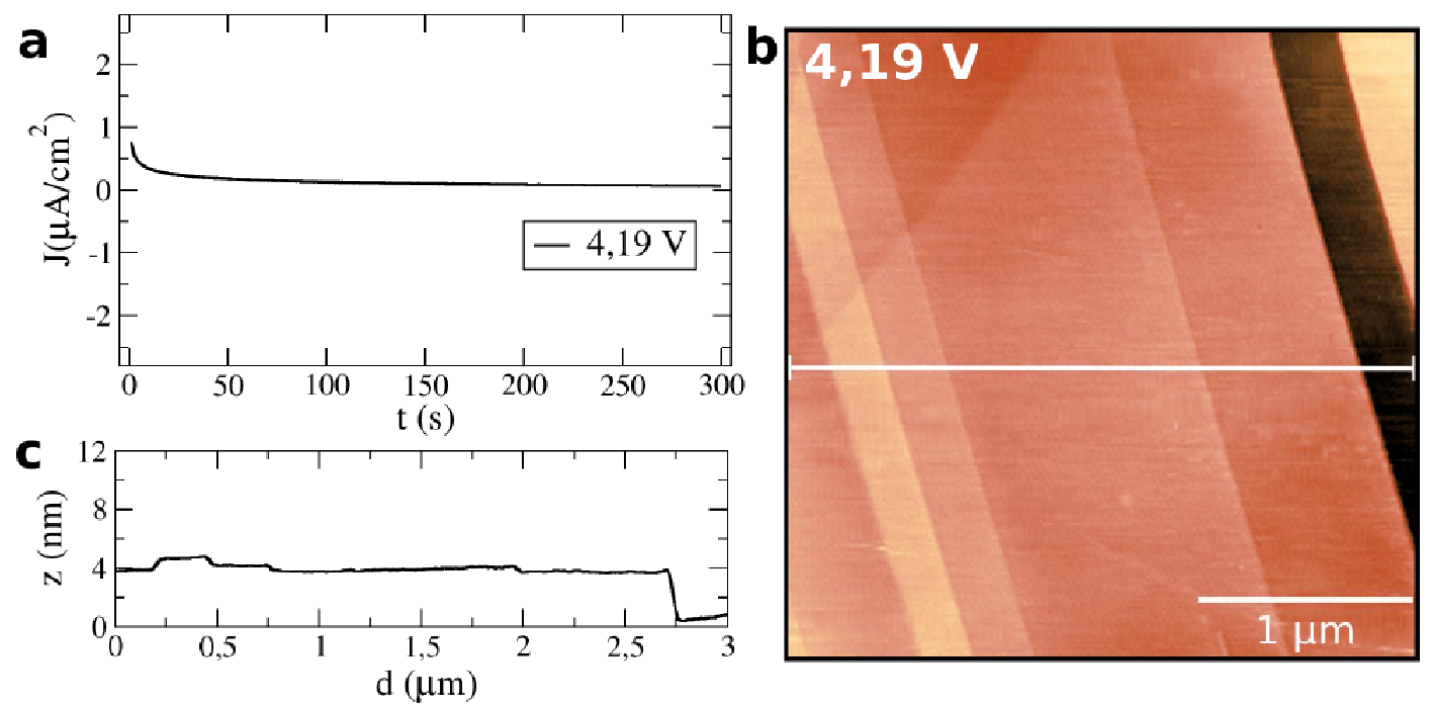

Figure 6. Oxidation of $\mathrm{Li}_{2} \mathrm{O}_{2}$ under chronoamperometry at $4.19 \mathrm{~V}$ during $300 \mathrm{~s}$ in LiTFSI $0.5 \mathrm{M}$ in $\mathrm{O}_{2}$-saturated DMSO. a) Current density as a function of time; b) In situ AFM image of HOPG surface after the OOR; c) Topographic profile measured along the white line indicated on the image.

Starting with a clean HOPG surface (Figure 6b), a CA was performed at a reduction potential of $2.7 \mathrm{~V}$ during 150 seconds (Figure 7a). In this case the current does not vanish either, suggesting 
that still exist uncovered HOPG regions where the $\mathrm{O}_{2}$ can be reduced to $\mathrm{O}^{2-}$. The AFM image in Figure $7 \mathrm{~b}$ shows the HOPG surface covered with $\mathrm{Li}_{2} \mathrm{O}_{2}$ nanoparticles ( $20 \mathrm{~nm}$ height) with small holes (marked with white circles) or interstitial sites that are possible regions where the $\mathrm{O}_{2}$ reduction could still proceed.
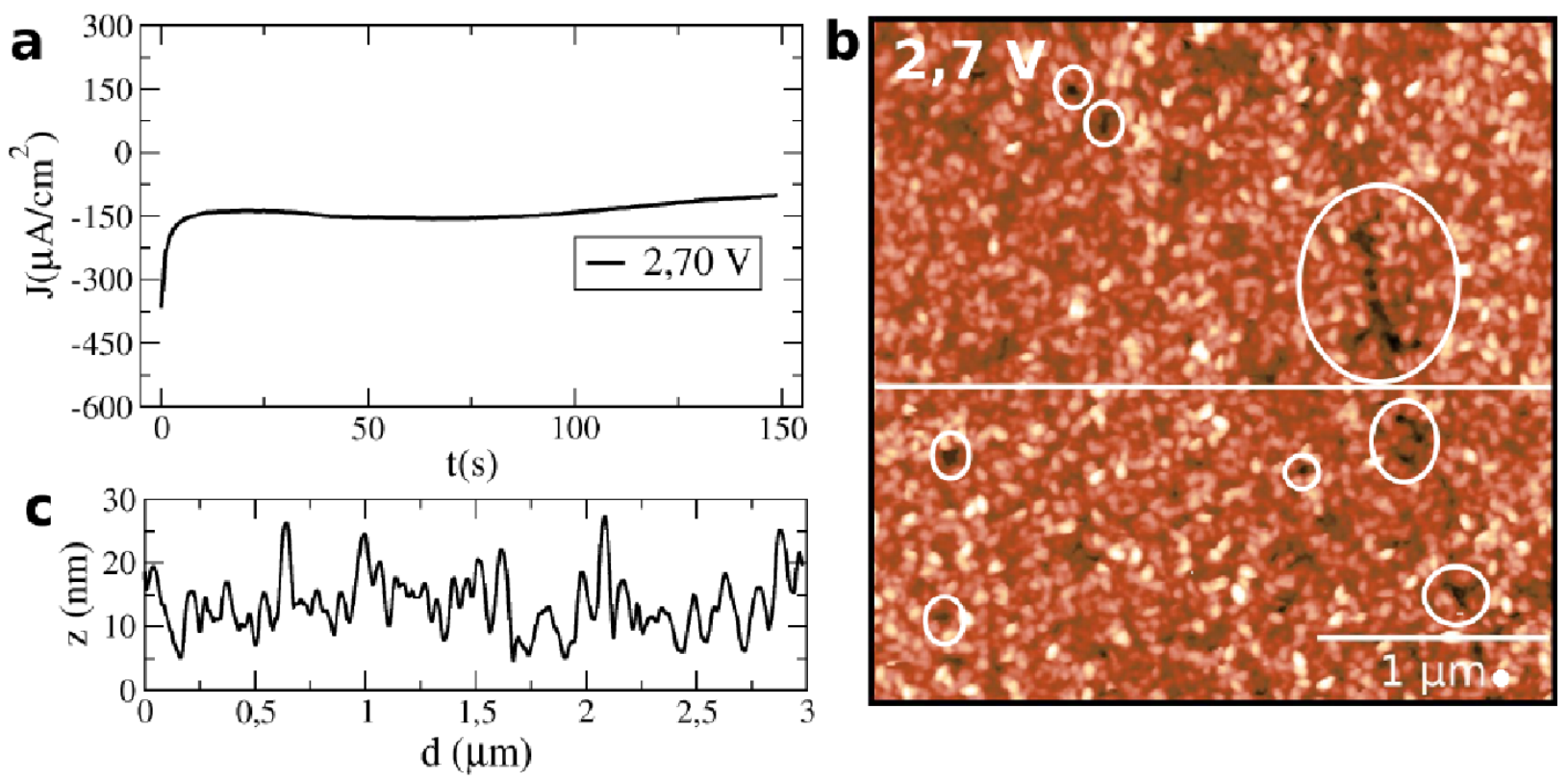

Figure 7. $\mathrm{Li}_{2} \mathrm{O}_{2}$ formation under chronoamperometry at $2.7 \mathrm{~V}$ during $150 \mathrm{~s}$ in LiTFSI $0.5 \mathrm{M}$ in $\mathrm{O}_{2}$-saturated DMSO. a) Current density as a function of time; b) in-situ AFM image of HOPG surface after the ORR; c) Topographic profile measured along the white line indicated on the image.

A zoom on Figure $7 \mathrm{~b}$ allows to observe the detailed morphology of the $\mathrm{Li}_{2} \mathrm{O}_{2}$ nanoparticles (Figure 8). The worn-like nanoparticles observed in this AFM image differ from the rod-shaped nanoplates formed on HOPG, reported by Byon et al. ${ }^{17,19}$ using an electrolyte based on the TEGDME solvent, These alternative morphologies may be the evidence of the occurrence of two different formation mechanisms of the discharge products. On one hand, the use of a solvent with a high donor number 
$(\mathrm{DN})$ as DMSO $(\mathrm{ND}=30)$ would promote the solution mechanism, while TEGDME, having a low donor number $(\mathrm{ND}=16)$ would favor a surface mechanism. ${ }^{11}$
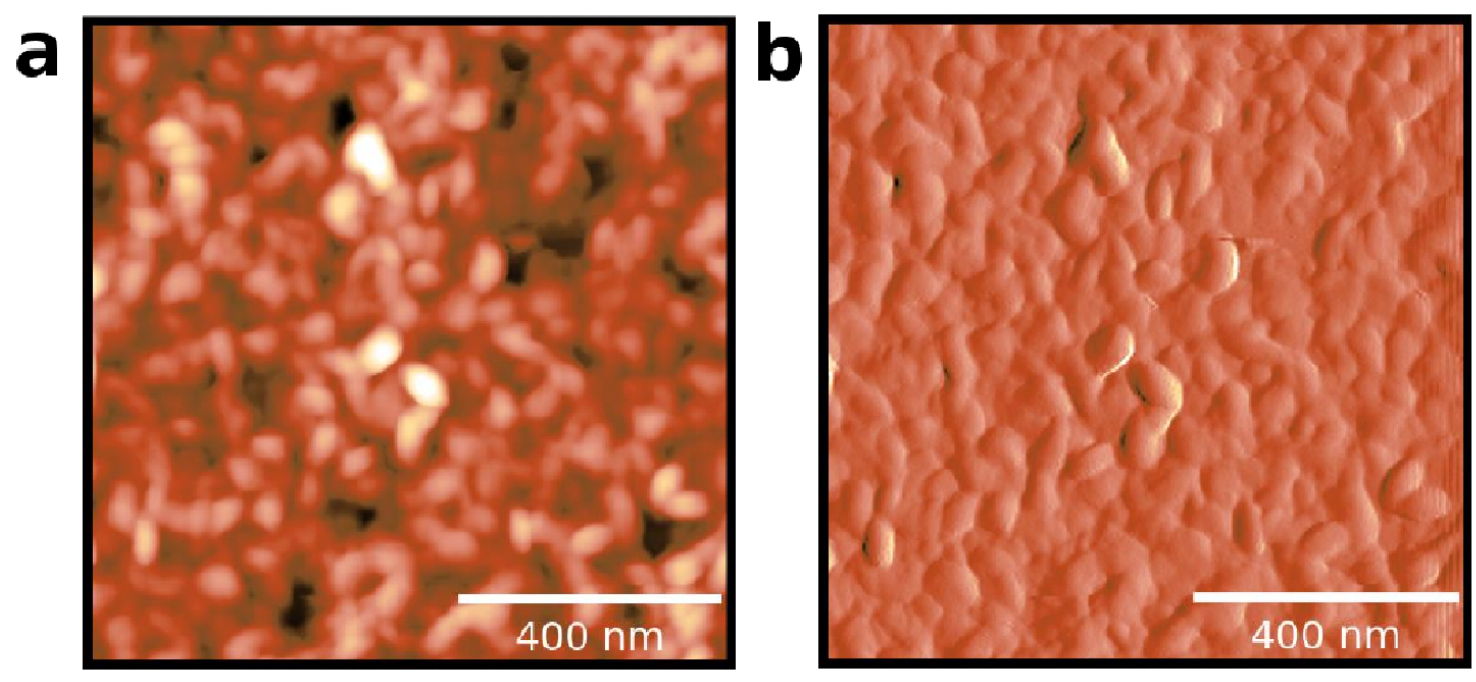

Figure 8. Zoom of the AFM image in Figure 4b: a) topography; b) deflection.

Starting with a clean HOPG surface, the CV described in Figures 4 and 5 was repeated, this time at a scan rate of $5 \mathrm{mV} / \mathrm{s}$. Figure 9 a shows the corresponding voltagram where two cathodic peaks at 2.57 and $2.43 \mathrm{~V}$ are observed, while three anodic peaks at $3.5 \mathrm{~V}, 4.0 \mathrm{~V}$, and $4.3 \mathrm{~V}$ are present. It is worth mentioning that at a slower scan rate the oxidation peaks become closer because the $\mathrm{O}_{2}$ molecules have more time for diffusing toward the cathode, continuing the ORR. Moreover, the $\mathrm{LiO}_{2}$ has now enough time to diffuse in the electrolyte, reducing the chance of being reduced again to $\mathrm{Li}_{2} \mathrm{O}_{2}$ on the cathode surface. In addition, the low intensity of the cathodic peaks is a signal of the asymmetry of the ORR and OER. 


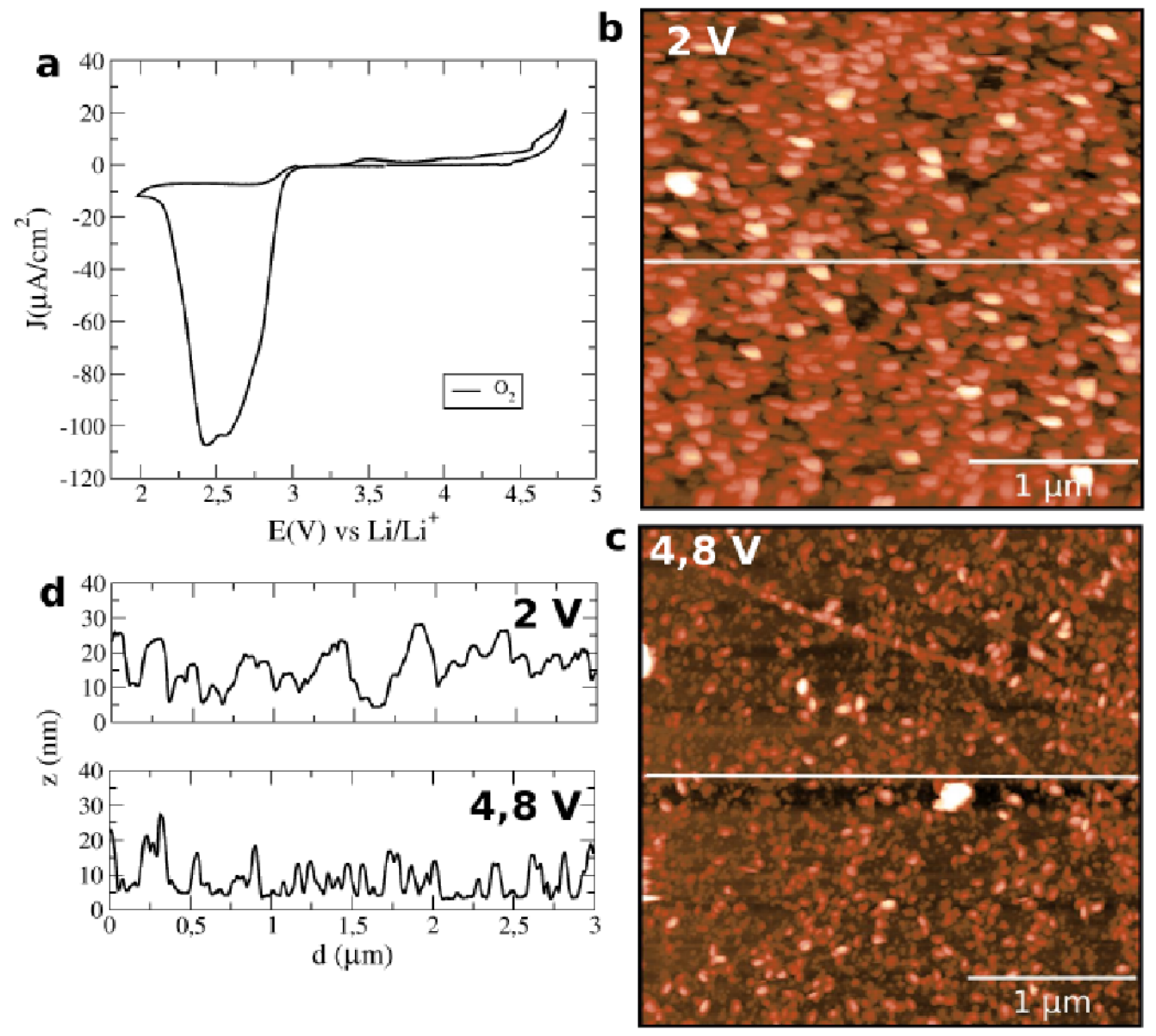

Figure 9. a) CV of LiFSI 0.1 $\mathrm{M}$ in DMSO saturated with $\mathrm{O}_{2}$ on HOPG (scan rate: $5 \mathrm{mV} / \mathrm{s}$ ); b) and c) in-situ AFM images AFM of the HOPG surface after the cathodic scan at $2 \mathrm{~V}$, and the anodic scan at $4.8 \mathrm{~V}$, respectively; d) Topographic profiles measured along the white lines indicated on the images.

Figures $9 \mathrm{~b}$ and 9c, show the in-situ AFM images taken during the CV, after the cathodic scan, at $2.0 \mathrm{~V}$ and the anodic scan at 4.8 V. During the cathodic scan, a number of nanoparticles $\sim 100 \mathrm{~nm}$ in diameter and $\sim 30 \mathrm{~nm}$ height, cover the HOPG surface (Figure 9b). After the anodic scan a reduction in the size of the nanoparticles on the surface size was observed (Figure 9c). The topographic profiles shown in Figure 9d, reveal an scenario similar to that previously described, 
where the OER on the bigger size $\mathrm{Li}_{2} \mathrm{O}_{2}$ nanoparticles initiates at the lateral walls. However, in this case it is also observed a remarkable diminishing of the particles height.

A zoom of Figure 9b, shown in Figure 10, allows to see the detailed morphology of the nanoparticles.
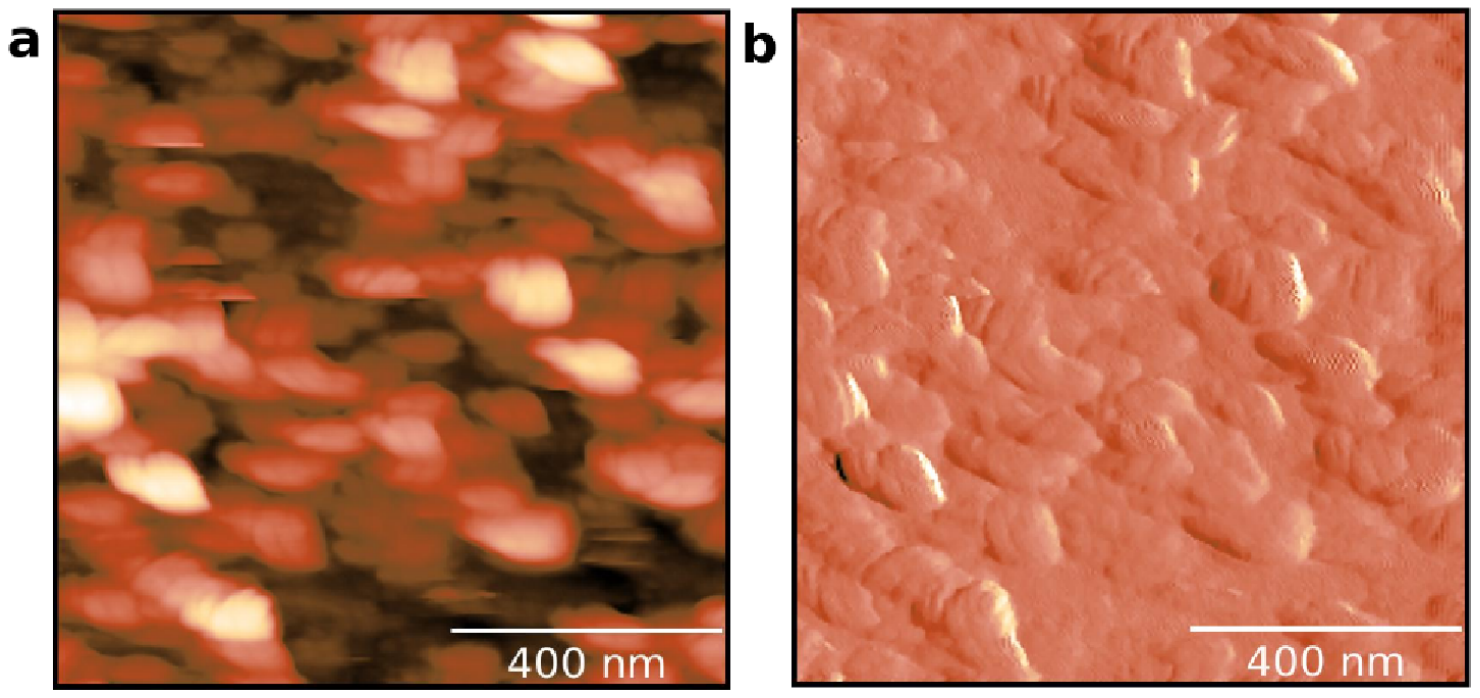

Figure 10. Zoom of the AFM image in Figure 8b: a) topography; b) deflection.

\section{Conclusions}

In summary, we developed an experimental technique, called Flow Electrochemical Atomic Force Microscopy, which allows the in-situ characterization of $\mathrm{Li}_{2} \mathrm{O}_{2}$ morphology during its formation and electrochemical oxidation. This experimental setup does not require placing the AFM inside a glove box, representing an advantage against the EC-AFM used in the previous works aforementioned. The system was tested with a model cell of the LOB in which a HOPG was used as cathode and a $0.5 \mathrm{M}$ solution of LiTFSI in DMSO $\mathrm{O}_{2}$-saturated as electrolyte. This cell allows us to visualise the oxidation process in thin $\mathrm{Li}_{2} \mathrm{O}_{2}$ deposits, which begins in the thinnest areas of the deposit and then proceeds laterally in the thickest areas. Additionally, it was observed the formation of larger nanoparticles with elongated and spherical globular shape, attributed to the solution mechanism of $\mathrm{Li}_{2} \mathrm{O}_{2}$ formation. The oxidation of these nanoparticles, on the other hand, 
seems to follow a bottom-up oxidation mechanism, described by a significant reduction in the height of the particles.

It is worth noting that the implementation of the FE-AFM technique represents an advance for the development of future research that seeks new cathode materials that facilitate the formation and decomposition of $\mathrm{Li}_{2} \mathrm{O}_{2}$.

\section{Author Information}

Corresponding Author E-mail: hrcorti@tandar.cnea.gov.ar

ORCID

Henry A. Cortés: 0000-0002-2361-5193

Horacio R. Corti: 0000-0003-4718-5236

\section{Acknowledgement}

This work was supported by CONICET (PIP 112201301 00808). HRC is a research fellow of CONICET. HAC thank doctoral fellowships by CONICET.

\section{References}

1. K. M. Abraham, Z. A. Jiang, Polymer Electrolyte-Based Rechargeable Lithium/Oxygen Battery. J. Electrochem. Soc. 143 (1996) 1-5.

2. X. Zhang, X. G. Wang, Z. Xie, Z. Zhou, Recent Progress in Rechargeable Alkali Metal-Air Batteries. Green Energy Environ. 1 (2016) 4-17. 
3. G. Girishkumar, B. McCloskey, A. C. Lunz, S. Swanson, W. Wilcke, Lithium-air battery: Promise and challenges. J. Phys. Chem. Lett. 1 (2010) 2193-2203.

4. P. G. Bruce, S. A. Freunberger, L. J. Hardwick, J.-M. Tarascon, $\mathrm{Li}-\mathrm{O}_{2}$ and Li-S batteries with high energy storage. Nat. Mater. 11 (2012) 19-29.

5. A. C. Luntz, B. D. McCloskey, Nonaqueous Li-Air Batteries: A Status Report, Chem. Rev. 114 (2014) 11721-11750.

6. P. A. N. Imanishi, A .C. Luntz, P. Bruce, The Lithium Air Battery, Springer, New York, 2014.

7. C. O. Laoire, S. Mukerjee, K. M. Abraham, E. J. Plichta, M. A. Hendrickson, Elucidating the mechanism of oxygen reduction for lithium-air battery applications. J. Phys. Chem. C 113 (2009), 20127-20134.

8. D. Aurbach, B. D. McCloskey, L. F. Nazar, P. G. Bruce, Advances in understanding mechanisms underpinning lithium-air batteries. Nat. Energy 1 (2016) 16128.

9. L. Johnson, C. Li, Z. Liu, Y. Chen, S. A. Freunberger, F. -M. Tarascon, P. C., B. B. Praveen, K. Dholakia, P. G. Bruce, The role of $\mathrm{LiO}_{2}$ solubility in $\mathrm{O}_{2}$ reduction in aprotic solvents and its consequences for $\mathrm{Li}-\mathrm{O}_{2}$ batteries. Nat. Chem. 6 (2014) 1091-1099.

10. B. D. McCloskey, C. M. Burke, J. E. Nichols, S. E. Renfrew, Mechanistic insights for the development of $\mathrm{Li}-\mathrm{O}_{2}$ battery materials: Addressing $\mathrm{Li}_{2} \mathrm{O}_{2}$ conductivity limitations and electrolyte and cathode instabilities. Chem. Commun. 51 (2015) 12701-12715.

11. Y. Wang, N. C. Lai, Y. R. Lu, Y. Zhou, C. L. Dong, Y. C. Lu, A solvent-controlled oxidation mechanism of $\mathrm{Li}_{2} \mathrm{O}_{2}$ in lithium-oxygen batteries. Joule 2 (2018) 2364-2380.

12. D. Sharon, D. Hirsberg, M. Salama, M. Afri, A. A. Frimer, M. Noked, W. Kwak, Y. K. Sun, D. Aurbach, Mechanistic role of $\mathrm{Li}^{+}$dissociation level in aprotic $\mathrm{Li}_{-} \mathrm{O}_{2}$ battery. ACS Appl. Mater. Interfaces 8 (2016) 5300-5307. 
13. G. Horwitz, M. Factorovich, J. Rodriguez, D. Laria, H. R. Corti, Ionic Transport and Speciation of Lithium Salts in Glymes: Experimental and Theoretical Results for Electrolytes of Interest for Lithium-Air Batteries. ACS Omega 3 (2018) 11205-11215.

14. S. Yang, J.X. Wu, B.G. Yan, L. Li, Y. Sun, L. Lu, K. Zeng, Nanoscale characterization of charged/discharged lithium-rich thin film cathode by scanning probe microscopy techniques, J. Power Sources 352 (2017) 9-17.

15. S. Wang, Q. Liu, C. Zhao, F. Lv, X. Qin, H. Du, F. Kang, B. Li, Advances in understanding materials for rechargeable Lithium batteries by atomic force microscopy, Energy Environ. Mater. 1 (2018) 28-40.

16. Z. Weidong, S. Wentao, C. Ling-Zhi, W. Deyu, L. Hong, F. Besenbacher, H. Fuqiang, S. Cai, Beyond imaging: Applications of atomic force microscopy for the study of Lithium-ion batteries, Ultramicroscopy 204 (2019) 34-48.

17. R. Wen, M. Hong and H. R. Byon, In situ AFM imaging of $\mathrm{Li}^{-} \mathrm{O}_{2}$ electrochemical reaction on highly oriented pyrolytic graphite with ether-based electrolyte, J. Am. Chem. Soc. 135 (2013) 10870-10876.

18. M. Hong, C. Yang, R. A. Wong, A. Nakao, H. C. Choi, H. R. Byon, Determining the facile routes for oxygen evolution reaction by probing of $\mathrm{Li}_{-} \mathrm{O}_{2}$ cells with conformal $\mathrm{Li}_{2} \mathrm{O}_{2}$ films, J. Am. Chem. Soc. 140 (2018) 6190-6193.

19. R. Wen, H. R. Byon, In situ monitoring of the $\mathrm{Li}^{-} \mathrm{O}_{2}$ electrochemical reaction on nanoporous gold using electrochemical AFM, Chem. Commun. 50 (2014) 2628-2631.

20. C. Liu, S. Ye, In situ atomic force microscopy (AFM) study of oxygen reduction reaction on a gold electrode surface in a dimethyl sulfoxide (DMSO)-based electrolyte solution, J. Phys. Chem. C 120 (2016) 25246-25255. 
21. Z.-Z. Shen, S.-Y. Lang, Y. Shi, J.-M. Ma, R. Wen, L.-J. Wan, Revealing the surface effect of the soluble catalyst on oxygen reduction/evolution in $\mathrm{Li}-\mathrm{O}_{2}$ batteries, J. Am. Chem. Soc. 141 (2019) 6900-6905.

22. K. Virwani, Y. Ansari, K. Nguyen, F. J. A. Moreno-Ortiz, J. Kim, M. J. Giammona, H.-C. Kim, Y.-H. La, In situ AFM visualization of $\mathrm{Li}_{-} \mathrm{O}_{2}$ battery discharge products during redox cycling in an atmospherically controlled sample cell, Beilstein J. Nanotechnol. 10 (2019) 930-940.

23. S. E. Herrera, A. Y. Tesio, R. Clarenc, E. J. Calvo, AFM study of oxygen reduction products on HOPG in the LiPF - DMSO electrolyte, Phys. Chem. Chem. Phys. 16 (2014) 9925-9929.

24. F. Marchini,S. E. Herrera, E. J. Calvo, F. J. Williams, Surface studies of lithium-oxygen redox reactions over HOPG, Surf. Sci. 646 (2016) 154-159.

25. S. Matsuda, Y. Kubo, K. Uosaki, K. Hashimoto, S. Nakanishi, Improved energy capacity of aprotic $\mathrm{Li}-\mathrm{O}_{2}$ batteries by forming Cl-incorporated $\mathrm{Li}_{2} \mathrm{O}_{2}$ as the discharge product, J. Phys. Chem. C 120 (2016) 13360-13365.

26. H. A. Cortés Páez, V. L. Vildosola, A. Barral, H. R. Corti, Effect of halogen dopants on the $\mathrm{Li}_{2} \mathrm{O}_{2}$.propertis: Is chloride special?. Phys. Chem. Chem. Phys. 20 (2018) 16924-16931.

xx. A. A. Abu Quba, G. E. Schaumann, M. Karagulyan, D. Diehl, A new approach for repeated tip-sample relocation for AFM imaging of nano and micro sized particles and cells in liquid environment, Ultramicroscopy 211 (2020) 112945.

xx. J. Wang, G. Huang, J.-M. Yan, J.-L. Ma, T. Liu, M.-M. Shi, Y. Yu, M.-M. Zhang, J.-L. Tang, X.-B. Zhang, Hybrid solid electrolyte enabled dendrite-free Li anodes for high-performance quasi-solid-state lithium-oxygen batteries, Nat. Sci. Rev. 8 (2021) nwaa150. 
xx. Y. Gu, W.-W. Wang, Y.-J. Li, Q.-H. Wu, S. Tang, J.-W. Yan, M.-S. Zheng, D.-Y. Wu, C.-H. Fan, W.-Q. Hu, Z.-B. Chen, Y. Fang, Q.-H. Zhang, Q.-F. Dong, B.-W. Mao, Designable ultra-smooth ultra-thin solid-electrolyte interphases of three alkali metal anodes, Nat. Commun. 9 (2018) 1339. 